\title{
Efficacy and Safety of Epilepsy Surgery for Older Adult Patients with Refractory Epilepsy
}

This article was published in the following Dove Press journal:

Therapeutics and Clinical Risk Management

\section{Naoki Ichikawa \\ Ayataka Fujimoto (D) \\ Tohru Okanishi (D) \\ Keishiro Sato \\ Hideo Enoki}

Comprehensive Epilepsy Center, Seirei Hamamatsu General Hospital, Shizuoka, 430-8558, Japan
Correspondence: Ayataka Fujimoto Seirei Hamamatsu General Hospital, 2-12I2 Sumiyoshi, Nakaku, Hamamatsu, Shizuoka 430-8558, Japan

Tel +8I-53-474-2222

Fax +8I-53-475-7596

Email ataka_fuji@sis.seirei.or.jp
Purpose: The population of elderly patients with epilepsy has been growing rapidly and the chances of referring older patients with refractory epilepsy for surgical options could be increasing. In general, epilepsy surgery at higher ages has been less likely to be performed, because little is known regarding the risks and benefits in elderly patients. We, therefore, investigated surgical outcomes and comorbidities in a population $\geq 50$ years old who underwent epilepsy surgery.

Methods: Patients $\geq 50$ years old who underwent epilepsy surgery were identified from the database of our epilepsy center for the period from 2009 to 2017. Surgical complications and seizure outcome were reviewed, and seizure outcomes were evaluated using the International League Against Epilepsy (ILAE) surgery outcome scale.

Results: The mean age of 32 patients at the time of surgery was $56.1 \pm 5.1$ years. The mean duration of epilepsy was $23.4 \pm 18.5$ years and mean follow-up was $2.7 \pm 2.0$ years. As of the most recent visit, $56.3 \%$ of patients remained completely seizure-free (ILAE Class I). The surgery-related complication rate was $11.5 \%$, comprising permanent deficits in $3.8 \%$ and transient deficits in $7.7 \%$.

Conclusion: These results suggest that epilepsy surgery may represent a valuable approach in selected adult patients.

Keywords: epilepsy surgery, older adults, elderly, seizure outcome, complications

\section{Introduction}

On the present epilepsy medication, the majority of patients with epilepsy can reach sustained remission with the first or second monotherapy utilized, whereas approximately one-third continues to experience seizures despite adequate treatment ${ }^{1}$ and the burden of treatment-resistant epilepsy has remained fairly stable over the years despite the availability of new antiepileptic drugs, including those of thirdgeneration like brivaracetam, eslicarbazepine acetate and perampanel. ${ }^{2-5}$ Those drug-resistant epilepsy patients are the candidates of surgical treatment, also might include elderly populations. The population globally is aging rapidly, and this tendency is expected to continue and strengthen in future. ${ }^{6,7}$ Similarly, elderly patients represent the most rapidly growing segment of the population with epilepsy. ${ }^{8}$ Around 2000 , the elderly started to exceed children in terms of the incidence of epilepsy, and today the elderly show the highest incidence. ${ }^{9} \mathrm{New}-$ onset epilepsies in the elderly are mostly seen as symptomatic focal epilepsy, which is likely to be amenable to epilepsy surgery. ${ }^{8,10,11}$ The need for surgery for the elderly thus seems likely to be increasing over time. Although many elderly patients now live with epilepsy, very few centers are performing epilepsy surgery for the 
elderly. The optimal age for such surgery was previously considered to be between 12 and 30 years, ${ }^{12}$ and surgery in adults between 45 and 60 was approached with caution. ${ }^{13}$ The reasons for low rates of elderly surgery are considered to be the higher incidences of stroke, hemorrhage and tumors and the higher prevalence of comorbidities such as cardiovascular disease. ${ }^{9,14}$ Basically, comorbidities and other risk factors are more likely to be present with increasing age. ${ }^{15}$ This seems likely to result in a reluctance of surgeons to perform or patients to undergo such surgery. ${ }^{16}$ However, little is known regarding the surgical risks and benefits in elderly patients, because most studies have included subjects $<50$ years old. ${ }^{14}$ Older patients still tend to be underreported in general. ${ }^{17}$

If good surgical outcomes and minimal complications can be ensured, elderly individuals can be more confident in selecting the surgical option. This could, in turn, lead to better outcomes for epilepsy and better quality of life after surgery. This perspective seems very important for countries with increasingly elderly populations, particularly Japan as the most aged country in the world. ${ }^{18}$ The aims of the present retrospective study were to report our experience with surgical treatment for patients $\geq 50$ years old with refractory epilepsy and to investigate the efficacy and safety of surgery in this population.

\section{Methods}

\section{Study Design and Ethics Approval}

The ethics committee at Seirei Hamamatsu General Hospital approved the protocol for this study in accordance with the principles of the Declaration of Helsinki. Participants in this study were identified via a retrospective electronic chart review at the Comprehensive Epilepsy Center, Seirei Hamamatsu General Hospital. Written informed consent was obtained from all patients.

\section{Patients}

Patients who had undergone epilepsy surgery between August 2009 and November 2017 were identified from the database of our epilepsy center. Inclusion criteria were age $\geq 50$ years at the time of surgery and availability of postoperative information.

\section{Surgical Procedures}

All patients received standardized evaluations and had been diagnosed with refractory epilepsy. They accepted various procedures: resective epilepsy surgery, intracranial subdural grid and depth electrode insertion for extra-operative electrocorticographic monitoring, tumor removal, vagal nerve stimulation (VNS) implantation, replacement of the VNS device and corpus callosotomy. We included all procedures in this study.

\section{Evaluation of Complications}

We investigated surgery-related complications and also included complications of invasive examinations such as the Wada test.

\section{Outcome Measurement}

We established a group of patients who had undergone resective epilepsy surgery, removal of magnetic resonance imaging (MRI)-documented lesions and apparent epileptogenic tissue as suggested by preoperative evaluations. We searched for seizure-related outcomes in this group. Outcomes were determined through retrospective information from the most recent outpatient visit in accordance with the International League Against Epilepsy (ILAE) surgery outcome scale. ${ }^{19}$

\section{Results}

\section{Patient Characteristics}

We identified 32 patients (18 women, 14 men) who underwent epilepsy-related surgery. Mean age at epilepsy onset was 32.6 \pm 21.4 years (range, 1-68 years). Mean age at surgery was $56.1 \pm 5.1$ years (range, $50-68$ years). Mean duration of epilepsy prior to surgery was $23.4 \pm 18.5$ years (range, $<1-52$ years). Mean duration of follow-up was $2.7 \pm 2.0$ years (range, $<1-8$ years). These data are summarized in Table 1.

\section{Surgical Procedures}

We identified 52 surgeries, including 15 resective epilepsy surgeries, 15 intracranial electrode insertions, 7 tumor removal surgeries, 10 VNS implantations, 2 VNS replacements and 3 corpus callosotomies. These data are summarized in Table 2.

Table I Demographics and Characteristics of Patients $>50$ Years Old Who Underwent Epilepsy Surgery $(\mathrm{N}=32)$

\begin{tabular}{|l|l|}
\hline Gender (female) [n] (\%) & $18(56)$ \\
Age at onset [years] median, mean (range) & $24,32.6 \pm 21.4(\mathrm{I}-68)$ \\
Age at surgery [years] median, mean (range) & $55,56.1 \pm 5.1(50-68)$ \\
Epilepsy duration [years] median, mean (range) & $28,23.4 \pm 18.5(<1-52)$ \\
Follow-up [years] median, mean (range) & $2,2.7 \pm 2.0(<1-8)$ \\
\hline
\end{tabular}


Table 2 Detailed Surgical Procedures $(\mathrm{N}=52)$

\begin{tabular}{|l|l|}
\hline Resective epilepsy surgery [n] (\%) & $16(30.7)$ \\
Electrodes insertion [n] (\%) & $15(28.8)$ \\
Tumor removal [n] (\%) & $6(11.5)$ \\
VNS implantation [n] (\%) & $10(19.2)$ \\
VNS replacement [n] (\%) & $2(3.8)$ \\
Corpus Callosotomy [n] (\%) & $3(5.8)$ \\
\hline
\end{tabular}

\section{Complications}

Surgical complications were found in six cases (11.5\%). We underwent 15 cases with electrode insertion, four had intracranial hematoma. Two of which had to be evacuated (one of these two patients had a medical history of intracerebral hemorrhage and was eventually shown to have an arteriovenous malformation (AVM). The remaining two were observed. A different one patient with history of previous aneurysmal subarachnoid hemorrhage then had hydrocephalus followed by treatment with ventriculoperitoneal shunt (VP shunt). The last patient experienced cerebral infarction due to the Wada test. 20 patients who had Wada test performed; one patient had a cerebral infarction. The patient had transient neurological deficit and then was fully recovered.

Permanent neurological deficits were observed in two patients: one case who had hematoma evacuation has been severe disability (modified Rankin Scale V), the other one who had hematoma evacuation due to AVM has been hemianopia. Transient neurological deficits were observed in two patients: one case who had cerebral infarction at Wada test had hemiparesis that had resolved within a few days, and the other one case who had left temporal focal resection had aphasia that had resolved within a few weeks. No cases of death were associated with surgeries in this study. The data are summarized in Table 3.

\section{Seizure Outcome}

The present study reviewed 16 cases involving resective epilepsy surgery. At the time of final follow-up, 9 (56.3\%) of the 16 patients were documented as completely seizure-free (ILAE Class I), including $8(88.9 \%)$ of 9 patients who had undergone temporal lobe surgery. Twelve (75\%) of the 16 patients were classified as ILAE Class I-III (rare disabling seizure).

Histopathology in this group was hippocampal sclerosis (HS) in three cases and focal cortical dysplasia (FCD) in three. These data are summarized in Table 4.
Table 3 Neurological Deficits and Complications

\begin{tabular}{|l|l|}
\hline Total 6 Cases (n=6/52: I I.5\%) & \\
\hline Permanent deficits & $2(3.8 \%)$ \\
\hline Transient deficits \& asymptomatic & 4 (7.7\%) \\
\hline $\begin{array}{l}\text { Intracranial hematoma } \\
\text { Hematoma removal } \\
\text { Observation }\end{array}$ & $\begin{array}{l}(2) \\
(2)\end{array}$ \\
\hline Cerebral infarction & $\mathrm{I}$ \\
\hline Hydrocephalus & $\mathrm{I}$ \\
\hline $\begin{array}{l}\text { Invasive procedures } \\
\text { Electrodes insertion } \\
\text { Resective epilepsy surgery } \\
\text { Wada test }\end{array}$ & 4 \\
\hline
\end{tabular}

Table 4 Detailed Seizure Outcomes Using the ILAE Seizure Outcome Scale and Histopathology of Surgical Specimens

\begin{tabular}{|l|l|l|l|l|}
\hline N=16 & Temporal & Frontal & Multilober & Total \\
\hline ILAE Class I & 8 & & I & $9(56.3 \%)$ \\
Class II & I & & & I (6.3\%) \\
Class III & I & & I & (I2.5\%) \\
Class IV & 2 & I (25\%) \\
\hline & I2(75\%) & I (6.3\%) & $3(18.8 \%)$ & \\
\hline Histopathology & & & & 15 \\
HS & & & & $3(20 \%)$ \\
HS+AVM & & & & I (6.7\%) \\
AVM & & & & I (6.7\%) \\
FCD & & & & $3(20 \%)$ \\
Gliosis & & & & I (6.7\%) \\
Non specific & & & & $6(40 \%)$ \\
\hline
\end{tabular}

\section{Discussion}

This study investigated the surgical risks and outcomes in patients $\geq 50$ years old with refractory epilepsy.

In terms of surgical risk, our results showed that the surgically related complication rate $(11.5 \%)$ was similar to that seen in other studies of the same older patient group $(10-10.9 \%){ }^{15,20}$ However, this complication rate was higher than that seen in younger patients. In large series of younger patients $7.5-8.9 \%$ of minor complications have been reported. $^{20,21}$ Some studies have reported a significant increase in surgical risk with age. ${ }^{14,20}$ In those studies, complications were mostly transient and even cases with permanent deficits were able to take care of themselves. In our study, permanent deficit was noted in 2 patients $(3.8 \%, 4.9 \%$ excluded VNS surgery), and transient deficits and 
asymptomatic were noted in 4 patients $(7.7 \%, 9.8 \%$ excluded VNS surgery). No neurological deficits cases provided in VNS surgery. Two of our 6 complicated cases had clinical histories of AVM and SAH, and were complicated by intracranial hematoma and hydrocephalus, respectively. Thus, some difficulties existed in comparing our complication rates to those of other studies and other age groups, because of the heterogeneity of histopathology and surgical procedures. Older patients, therefore, had a risk of complications in epilepsy surgery, but risk maybe overemphasized, though needs further study.

In terms of seizure outcomes, our results showed that $10(62.5 \%)$ of 16 patients achieved a seizure-free state with or without aura (ILAE Class I-II), 9 (56.3\%) were completely seizure-free (ILAE I) and 12 (75\%) involved rare disabling seizure (ILAE Class I-III). This seizure outcome was almost equivalent to that of other studies and also equivalent to the younger adults in other studies. $^{8,22,23}$ As in our analysis, epilepsy surgery was equally effective in both younger and older patients, and older age did not preclude a favorable seizure outcome.

In summary, this study suggested that older patients with epilepsy should not be considered contraindicated for surgical treatment, despite a higher risk of surgical complications compared with younger patients. We should not lose the opportunities for treatment by emphasizing the risk too much. Careful assessment and sufficient preoperative evaluation would lead to selection of the appropriate candidates and improved affordability of effective treatment in elderly epilepsy patients.

Several limitations of this study should be acknowledged. Firstly, our sample size was small. And the data were collected retrospectively. Therefore, the results have to be interpreted with caution. A younger control group was absent, although our data showed similar characteristics compared to elderly patients in other studies. Furthermore, we did not evaluate pre- and post-cognitive function associated with surgery. This viewpoint would be one of the chief concerns regarding epilepsy surgery in elderly patients. Some studies have reported no significant cognitive morbidities in most elderly individuals. ${ }^{15,23}$

\section{Conclusion}

The present study demonstrated that epilepsy surgery for patients $\geq 50$ years old provided equal efficacy compared with younger adult patients. Although the surgical complication rate in older patients was higher than that in younger patients, most complications were transient deficits, and permanent deficits were not higher than younger adults with similar invasive procedures.

\section{Author Contributions}

All authors contributed to data analysis, drafting or revising the article, gave final approval of the version to be published, and agree to be accountable for all aspects of the work.

\section{Disclosure}

The authors report no conflicts of interest concerning the patients or methods used in this study or the findings specified in this paper. All authors certify that they have no affiliations with or involvement in any organization or entity with any financial interest (such as honoraria; educational grants; participation in speakers' bureaus; membership, employment, consultancies, stock ownership, or other equity interest; and expert testimony or patentlicensing arrangements), or non-financial interest (such as personal or professional relationships, affiliations, knowledge or beliefs) in the subject matter or materials discussed in this manuscript.

\section{References}

1. Lattanzi S, Trinka E, Del Giovane C, Nardone R, Silvestrini M, Brigo F. Antiepileptic drug monotherapy for epilepsy in the elderly: a systematic review and network meta-analysis. Epilepsia. 2019;60 (11):2245-2254. doi:10.1111/epi.v60.11

2. Lattanzi S, Striano P. The impact of perampanel and targeting AMPA transmission on anti-seizure drug discovery. Expert Opin Drug Discov. 2019;14(3):195-197. doi:10.1080/17460441.2019.1566318

3. Lattanzi S, Cagnetti C, Foschi N, Lorusso A, Provinciali L, Silvestrini M. Eslicarbazepine acetate as adjunctive treatment in partial-onset epilepsy. Acta Neurol Scand. 2018;137(1):29-32. doi:10. 1111/ane.2018.137.issue-1

4. Lattanzi S, Brigo F, Cagnetti C, Verrotti A, Zaccara G, Silvestrini M. Eslicarbazepine acetate in the treatment of adults with partial-onset epilepsy: an evidence-based review of efficacy, safety and place in therapy. Core Evid. 2018;13:21-31. doi:10.2147/CE.S142858

5. Lattanzi S, Cagnetti C, Foschi N, Provinciali L, Silvestrini M. Brivaracetam add-on for refractory focal epilepsy: a systematic review and meta-analysis. Neurology. 2016;86(14):1344-1352. doi:10.1212/ WNL.0000000000002545

6. Brodie MJEA, Kwan P. Epilepsy in later life. Lancet Neurol. 2009;8:1019-1030. doi:10.1016/S1474-4422(09)70240-6

7. Fujimoto A, Okanishi T, Masuda Y, et al. Short duration of focal onset awareness and impaired awareness seizure are characteristic features of epilepsy in elderly patients. Neuropsychiatr Dis Treat. 2018;14: 2879-2887. doi:10.2147/NDT

8. Lang JD, Grell L, Hagge M, et al. Long-term outcome after epilepsy surgery in older adults. Seizure. 2018;57:56-62. doi:10.1016/j.seizure. 2018.02.012

9. Sillanpaa M, Lastunen S, Helenius H, Schmidt D. Regional differences and secular trends in the incidence of epilepsy in Finland: a nationwide 23-year registry study. Epilepsia. 2011;52(10):1857-1867. doi:10.11 $11 / \mathrm{j} .1528-1167.2011 .03186 . \mathrm{x}$ 
10. Acharya JNAV, Acharya V. Epilepsy in the elderly: special considerations and challenges. Ann Indian Acad Neurol. 2014;17:S18-26. doi:10.4103/0972-2327.128645

11. Luhdorf KJL, Plesner AM. Etiology of seizures in the elderly. Epilepsia. 1986;27:458-463. doi:10.1111/j.1528-1157.1986.tb03567.x

12. Casino G, Sharbrough F, Hirschorn K, Marsh W. Surgery for focal epilepsy in the older patient. Neurology. 1991;41(9):1415-1417. doi:10.1212/WNL.41.9.1415

13. Dewar S, Eliashiv D, Walshaw PD, Engel J Jr., Fried I, Moseley BD. Safety, efficacy, and life satisfaction following epilepsy surgery in patients aged 60 years and older. J Neurosurg. 2016;124(4):945-951. doi:10.3171/2015.3.JNS142317

14. Grivas A, Schramm J, Kral T, et al. Surgical treatment for refractory temporal lobe epilepsy in the elderly: seizure outcome and neuropsychological sequels compared with a younger cohort. Epilepsia. 2006;47(8):1364-1372. doi:10.1111/epi.2006.47.issue-8

15. d' Orio P, Pelliccia V, Gozzo F, et al. Epilepsy surgery in patients older than 50 years: effectiveness, safety, and predictors of outcome. Seizure. 2017;50:60-66. doi:10.1016/j.seizure.2017.06.003

16. Erba GMP, Pupillo E, Eghi E. OPTEFF group acceptance of epilepsy surgery among adults with epilepsy-what do patients? Epilepsy Behav. 2012;24:352-358. doi:10.1016/j.yebeh.2012.04.126
17. Forsgren LBE, Oun A, Sillanpaa M. The epidemiology of epilepsy in Europe - a systematic review. Eur J Neurol. 2005;12:245-253. doi:10.1111/j.1468-1331.2004.00992.x

18. Japan COGo. Annual Report on the Aging Society. Cabinet Office Government of Japan. 2016.

19. Wieser WTB HG, Fish D, Goldensohn E, et al. ILAE commission report. Proposal for a new classification of outcome with respect to epileptic seizures following epilepsy surgery. Epilepsia. 2001;42 (2):282-286. doi:10.1046/j.1528-1157.2001.4220282.x

20. Bjellvi J, Flink R, Rydenhag B, Malmgren K. Complications of epilepsy surgery in Sweden 1996-2010: a prospective, population-based study. J Neurosurg. 2015;122(3):519-525. doi:10.3171/2014.9.JNS132679

21. Rydenhag B, Silander HC. Complications of epilepsy surgery after 654 procedures in Sweden, September 1990-1995: a multicenter study based on the Swedish National Epilepsy Surgery Register. Neurosurgery. 2001;49(1):51-57. doi:10.1097/00006123-200107000-00007

22. O’Dwyer R, Byrne R, Lynn F, et al. Age is but a number when considering epilepsy surgery in older adults. Epilepsy Behav. 2018;91:9-12.

23. Punia V, Abdelkader A, Busch RM, et al. Time to push the age limit: epilepsy surgery in patients 60 years or older. Epilepsia Open. 2018;3 (1):73-80. doi:10.1002/epi4.12099
Therapeutics and Clinical Risk Management

\section{Publish your work in this journal}

Therapeutics and Clinical Risk Management is an international, peerreviewed journal of clinical therapeutics and risk management, focusing on concise rapid reporting of clinical studies in all therapeutic areas, outcomes, safety, and programs for the effective, safe, and sustained use of medicines. This journal is indexed on PubMed Central, CAS,

\section{Dovepress}

EMBase, Scopus and the Elsevier Bibliographic databases. The manuscript management system is completely online and includes a very quick and fair peer-review system, which is all easy to use. Visit http://www.dovepress.com/testimonials.php to read real quotes from published authors. 